\title{
Análise da função renal de pacientes submetidos ao tratamento com Everolimo comparada com os que não utilizam esse medicamento após transplante hepático, em Blumenau-SC.
}

\author{
Marcelo Augusto Scheidemantel Nogara ${ }^{1}$; Ana Carolina de \\ Linhares²; Beatriz Bandeira de Andrade' ${ }^{3}$; Charlles Camierchcki'; \\ Geovana Penteado Sartori ${ }^{5}$
}

\section{Resumo}

O estudo comparou a função renal de pacientes submetidos à terapia de imunossupressão com Everolimo e pacientes que não utilizaram o medicamento, fazendo o uso apenas de outros imunossupressores após transplante hepático. Este estudo foi realizado no período de janeiro de 2014 à dezembro de 2015 no Hospital Santa Isabel, em Blumenau, Santa Catarina. Foram obtidos dados de prontuários de 12 pacientes que utilizaram Everolimo e 23 pacientes não submetidos à droga. Os pacientes responderam a um termo de consentimento antes da inclusão. As variáveis analisadas foram: idade, sexo, raça, imunossupressor(es) em uso, nível de creatinina sérica e existência ou não de rejeição ao órgão transplantado. Para determinação da função renal foi calculada a taxa de filtração glomerular (TFG) pela fórmula MDRD, através do programa QxMD Software. Nos pacientes que fizeram uso de Everolimo, a média da TGF foi de 73,18 $\mathrm{mL} / \mathrm{min} / 1,73 \mathrm{~m}^{2}$, sendo o maior valor $198 \mathrm{~mL} / \mathrm{min} / 1,73 \mathrm{~m}^{2}$, e 20 $\mathrm{mL} / \mathrm{min} / 1,73 \mathrm{~m}^{2}$ o menor. Enquanto nos pacientes que não utilizaram esse medicamento, e que fizeram o uso de imunossupressores de outras classes (Inibidores da Calcineurina ou agentes antimetabólicos), a média da TFG foi de $69,19 \mathrm{~mL} / \mathrm{min} / 1,73 \mathrm{~m}^{2}$, sendo o valor mínimo encontrado 31 $\mathrm{mL} / \mathrm{min} / 1,73 \mathrm{~m}^{2}$ e máximo $124 \mathrm{~mL} / \mathrm{min} / 1,73 \mathrm{~m}^{2}$. Durante o estudo não foi observada relação entre a terapia imunossupressora de escolha e a rejeição ao órgão transplantado. Em conclusão, pacientes submetidos à imunoterapia com Everolimo após transplante hepático apresentaram melhor preservação da função renal em comparação ao grupo que não utilizou o imunossupressor, segundo o índice da taxa de filtração glomerular. 
Palavras Chave: imunossupressores; transplante hepático; taxa de filtração glomerular

1 Graduação em Medicina pela Universidade Federal do Paraná - UFPR (1989) e Mestrado em Gastroenterologia Clínica pela Universidade de São Paulo - UNIFESP (1997). Atualmente atua como médico gastroenterologista na cidade de Blumenau/SC e como docente para o Curso de Medicina da Universidade Regional de Blumenau - FURB. <marcelonogara@gmail.com>

2 Graduanda de Medicina pela Universidade Regional de Blumenau - FURB. <anacarolinalinhares@hotmail.com>

3 Graduanda de Medicina pela Universidade Regional de Blumenau - FURB. <andrade.beatriz@hotmail.com>

4 Graduando de Medicina pela Universidade Regional de Blumenau - FURB. <picollo.charlles@gmail.com>

5 Graduanda de Medicina pela Universidade Regional de Blumenau - FURB. <geovanasartori_1@hotmail.com> 